\title{
Unilaterally Enlarged Mandibular Foramina and Canal Associated With Hyperplastic Lymphatic Tissue of Inferior Alveolar Nerve: Case Report and Short Literature Survey
}

\author{
REINHARD E. FRIEDRICH ${ }^{1}$, JAKOB MATSCHKE ${ }^{2}$ and WALDEMAR WILCZAK ${ }^{3}$ \\ ${ }^{1}$ Department of Oral and Craniomaxillofacial Surgery, \\ Eppendorf University Hospital, University of Hamburg, Hamburg, Germany; \\ ${ }^{2}$ Institute of Neuropathology, Eppendorf University Hospital, University of Hamburg, Hamburg, Germany; \\ ${ }^{3}$ Institute of Pathology, Eppendorf University Hospital, University of Hamburg, Hamburg, Germany
}

\begin{abstract}
Background: Different phenomena can result in enlargement of mental foramen and mandibular canal. At the foreground of diagnosis is the assessment of the biological properties of the tissue which causes such detailed lesions of the skeleton. Case Report: This report describes a palpable mass at the site of the mental foramen with radiological evidence of an extensive enlargement of the bony portion of the inferior alveolar nerve. These findings were the reason for surgical exploration. Surprisingly, the mass was inflammatory tissue that had proliferated in the canal and foramina. The lesion had grown around the nerve and did not infiltrate it. The diagnosis of lymphatic hyperplasia was made. Other potential causes of the unusual radiological and clinical findings are explained with reference to the literature. Conclusion: Imaging does not provide a safe assessment of tumor biology. Surgical exploration with detailed tissue examination of the tumor provides the basis for appropriate therapy.
\end{abstract}

The mental foramen and mandibular canal of the human skull are structures that are largely symmetrical (1-8) and whose size and shape is constant within certain limits (8-10). Structural alterations of the mental foramen or mandibular canal such a widening of the lumen are a rare and usually incidentally finding recorded on plain radiographs $(2,5,6)$.

This article is freely accessible online.

Correspondence to: Professor R.E. Friedrich, MD, DMD, Ph.D., FEBOMFS, Department of Oral and Craniomaxillofacial Surgery, Eppendorf University Hospital, University of Hamburg, Martinist. 52, D-2046 Hamburg, Germany. Tel: +49 40741053259, e-mail: rfriedrich@uke.de

Key Words: Lymphatic hyperplasia, alveolar nerve, enlarged mandibular canal, enlarged mental foramen, magnetic resonance imaging.
The differential diagnosis of enlarged foramen and canal is manifold (11-56) and includes lymphoma (11-21), peripheral nerve sheath tumor (22-34), primary sarcoma (35-38), locally invasive carcinoma of the mucous membranes (39-45), distant metastasis $(46,47)$, osteomyelitis (48), lipoma (49, 50), hemangioma (51), idiopathic (52) and iatrogenic (53) bone defects, as well as various syndromes (54-56). Unilaterally enlarged mental foramen on a radiograph is suspected to indicate an underlying neoplastic process, predominantly tumors arising from lymphatic or nerve sheath cells $(1,13)$. However, radiological diagnosis of enlarged mental foramen does not allow determination of the phenomenon's biology. Indeed, mandibular canal and foramina enlargement may also be diagnosed in rare nontumorous entities such as Proteus syndrome (55) and multiple endocrine neoplasia (54). However, even in the field of rare medical syndromes, this finding is also relatively often reported. Enlargement of the nerve canal and mental foramen was occasionally identified in Noonan syndrome (56) and is considered a frequent radiological sign of neurofibromatosis type 1 (NF1) (27). The finding may occur unilaterally or bilaterally $(27,33)$. Pathogenesis of the findings is unclear with respect to NF1 (33), a tumorsuppressor gene disease, and other syndromes (54-56). On the other hand, nerve sheath tumors other than neurofibroma, in particular schwannoma, can also cause distension of the nerve canal. Intraosseous schwannoma is usually a sporadic tumor unrelated to NF2 (30). However, intraosseous schwannomas usually do not exhibit tubular but a rather cyst-like appearance on sectional $x$-ray images of the jaw (30) and the center of the lesion is more frequently in the distal portion of the mandibular corpus (32). Magnetic resonance imaging (MRI) is the preferred technique for imaging peripheral nerve sheath tumors (57). While MRI is recommended for peripheral nerve sheath tumour of the trigeminal nerve (58), it does not allow differentiation 
between entities of neurogenic tumors $(23,25)$. Malignant neoplasms of neurogenic and non-neurogenic origin can cause enlarged mandibular canal through osteolytic remodeling, reaching as far as the mental foramen (34). Despite imaging-assisted preliminary assessments of the suspected tumor entity, as well as knowledge of the prevalence, preferred locations and growth patterns of certain diseases with this pattern of radiological findings, the range of diagnoses remains very large (11-56).

The following report describes a space-occupying lesion first noticed at the mental foramen from which it was recognized that it reached into the canal and beyond. At first, from plain radiographs (59) the lesion had been estimated to be a benign nerve sheath tumor limited in size and extension to the site of the foramen. Surprisingly, the non-neurogenic lesion was of remarkable extension confined to the affected nerve. The lesion was characterized by non-neoplastic lymphatic tissue. A similar finding has been described in one other report only to our knowledge (60).

\section{Case Report}

The 59-year-old patient visited the outpatient clinic of the Department of Oral and Craniomaxillofacial Surgery on referral by her general practitioner. For several months, the patient had noticed a mass in the area of the left anterior side of the mandible and was worried that a neoplasm might be developing. Her doctor had also suspected a neoplasm, considering in his assessment the local conditions that had remained unchanged for months (constant volume, no functional failure) and argued in favour of the assumption of a schwannoma of the trigeminal nerve.

The patient was in a good general health condition and there was no evidence of a local trauma. During the physical examination, the sensitive qualities of the facial skin were unaffected. In particular, no dysesthesia was found in the mental nerve supply area. In the area of the left mandibular premolar region, a rounded, firm mass was palpable through the moveable skin. Upon pressure on this mass, the patient reported uncomfortable feeling of pressure that projected into the left lower lip region. Intraoral inspection disclosed unremarkable, intact mucosa. The palpation of the lesion showed it to be localized in the vestibular region of the left mandibular premolars. Mucosa was easy to move over the smooth, plumping prominence. The teeth of the third quadrant responded adequately to cold stimuli.

\section{Plain Radiography}

A panoramic view was made on which the enlarged mental foramen of the left side was apparent (Figure 1A and B). In addition, the mandibular canal of the left mandibular side was not defined in the area of the molars in this radiographic projection. This lack of delineation of the canal on the panoramic radiograph was accompanied by a substantial loss of the trabecular structure of the corpus to the angle of the jaw. The structure and position of the teeth adjacent to the foramen were unaffected. The patient was asked if X-rays had been taken during dental procedures. The patient was able to submit oral radiograph and panoramic radiograph of the jaws that had been prepared 7 and 8 years before, respectively (Figure 1C-F). On the panoramic radiograph, discrete asymmetry of the mental foramina was apparent, but only noticeable in retrospect (Figure $1 \mathrm{E}$ and $\mathrm{F}$ ). The findings had not changed during the former check ups. The comparison of the X-ray findings of the former and current panoramic views showed a change in the local findings, whereby the major difference between the two X-ray images was the greater mental foramen in the current image. In contrast, the blurred demarcation of the nerve canal of the left side of the jaw on both radiographs was essentially unchanged (Figure 1).

Cone beam computed tomography (CBCT). A CBCT of the mandible was performed in order to assess the skeletal lining of the nerve. The sectional views of the mandible confirmed loss of trabecular bone of the left corpus and absence of a sclerotic line delineating the nerve canal in this part of the bone. Furthermore, the images disclosed a substantial increase in size of both mental and mandibular foramen of the left mandibular side (Figure 2).

$M R I$. At the time, the preferred diagnosis of the intraosseous mass was a benign tumor of the nerve sheath origin. In order to better differentiate the structure of the soft tissue lesion within and around the nerve canal, 7-T MRI of the lower jaw was carried out (Figure 3). MRI of the left mandible revealed the mass to be a solid structure completely filling the enlarged canal. The homogeneous signal of the lesion was continuous from the mental to the mandibular foramen and beyond to the skull base. The intraosseous volume of the lesion presented in the MRI was consistent with the visible extent of loss of the internal spongious bone structure on plain radiographs and CBCT.

MRI showed an expansile, smooth-walled tumor that completely filled the mandibular canal. This tumor was hypointense in T1-weighted images and hyperintense in T2weighted. The intraosseous tumor protruded out of the bone in a mushroom-like pattern from both foramina (6 to $7 \mathrm{~mm}$ ) (Figure 3B-E). The growth of the mandibular lesion reached to the infratemporal fossa and cheek (Figure 3B, C and F). The intraosseous continuity of the lesion within the bone beyond the mental foramen was depicted down to the region of the left lateral incisors (Figure 3A and B). The signal at this site probably indicated the further intraosseous course of the tumorous nerve, which ends as the incisal nerve at the midline of the mandible. 


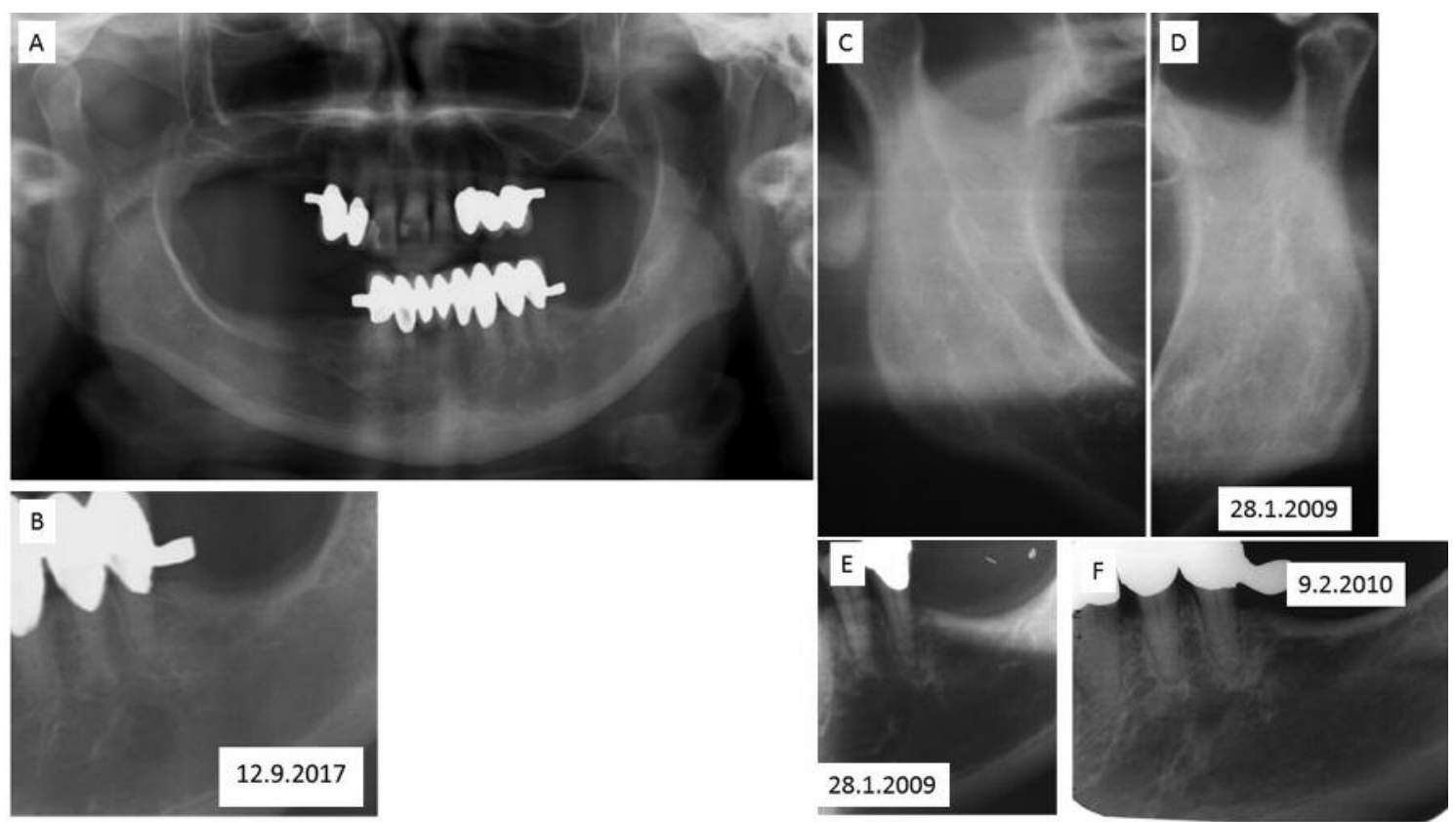

Figure 1. A: Panoramic view of the patient's jaws at the time of first investigation at an oral and maxillofacial surgery outpatient clinic (age: 59 years). A roundish translucent structure is located below the apices of mandibular left premolars that is detailed in B (cropped image of panoramic radiograph). On the right side, a small roundish translucent structure caudal to premolars is interpreted as mental foramen. The comparison of the mandibular canals shows that the canal on the left side is enlarged and more translucent than that of the opposite side. Comparison of right $(C)$ to left $(D)$ mandibular foramen region on panoramic view taken more than 8 years earlier (cropped images): Whereas sclerotic lines delineate upper and lower margin of the lumen of the right canal $(C)$, the left mandibular canal cannot be identified throughout the whole mandibular corpus and ramus $(D)$. At that time (50 years old), the mental foramen was slightly larger than that of the other side, but not noticeably deformed. F: This finding had not changed significantly 1 year later (after prosthetic restoration).

The intraosseous lesion had a total length of about $7.5 \mathrm{~cm}$ and a diameter of up to $1.4 \mathrm{~cm}$. The intraosseous part of the tumor had remodeled the displaced bone to varying degrees, as could be seen from the changes in tumor diameter in the corpus area. The dilatation of the foramina was at the mandibular up to $11 \mathrm{~mm}$ and at the mental up to $7 \mathrm{~mm}$. The lingual cortical bone appeared to be resorbed in the area of the left mandibular angle for a short distance (approximately $3 \mathrm{~mm}$ ). The surrounding soft-tissue areas were not infiltrated by the lesion. Small radial extensions of the strand-shaped hyperintense lesion within the bone were visible, aligned at right angles to the main lesion (Figure 3D and E). There was no perilesional edema. No intra-lesional cysts were detected. The basal part of the mandible was clearly separated from the hyperintense signals of the lesion. Although the radiological findings were compatible with the suspicion of a benign tumor arising from the peripheral nervous system, such as neurofibroma, it was not possible to rule out a malignant tumor, for example a malignant peripheral nerve sheath tumor, with the findings.

Surgery. The patient was informed about the findings and offered surgical revision of the lesion. However, the patient decided to wait and see whether the lesion would show spontaneous regression. Only one year later, the patient returned to the outpatient clinic and asked for surgical revision. The palpation of the tumor was unchanged. Pain on pressure had slightly increased in the meantime, but neither neurological deficits were recorded nor did the panoramic view show further enlargement of mental foramen and mandibular canal (Figure 4).

Under general anesthesia, the vestibular mucosa was detached from the bone and the left mental foramen was exposed. Inside the well-demarcated foramen, a soft-tissue lesion surrounded the terminal branches of the mental nerve. In contrast to the well-delineated, firm and smooth nerve fibers that were removed from the periosteum, the intraosseous lesion was much softer and easily lost integrity when touched. However, the jelly-like lesion was distributed in direct contact with nerve fibers. The enlarged foramen was freed from the tumor for a representative tissue sample, with a small additional tissue sample taken from a nerve to which the tumor was tightly attached. The mucosa was replaced, the wound was closed with sutures and the patient's further course was unremarkable. Postoperative hyperesthesia was recorded in the left chin area that slowly receded in followup. Surgical exploration is summarized in Figure 5. 

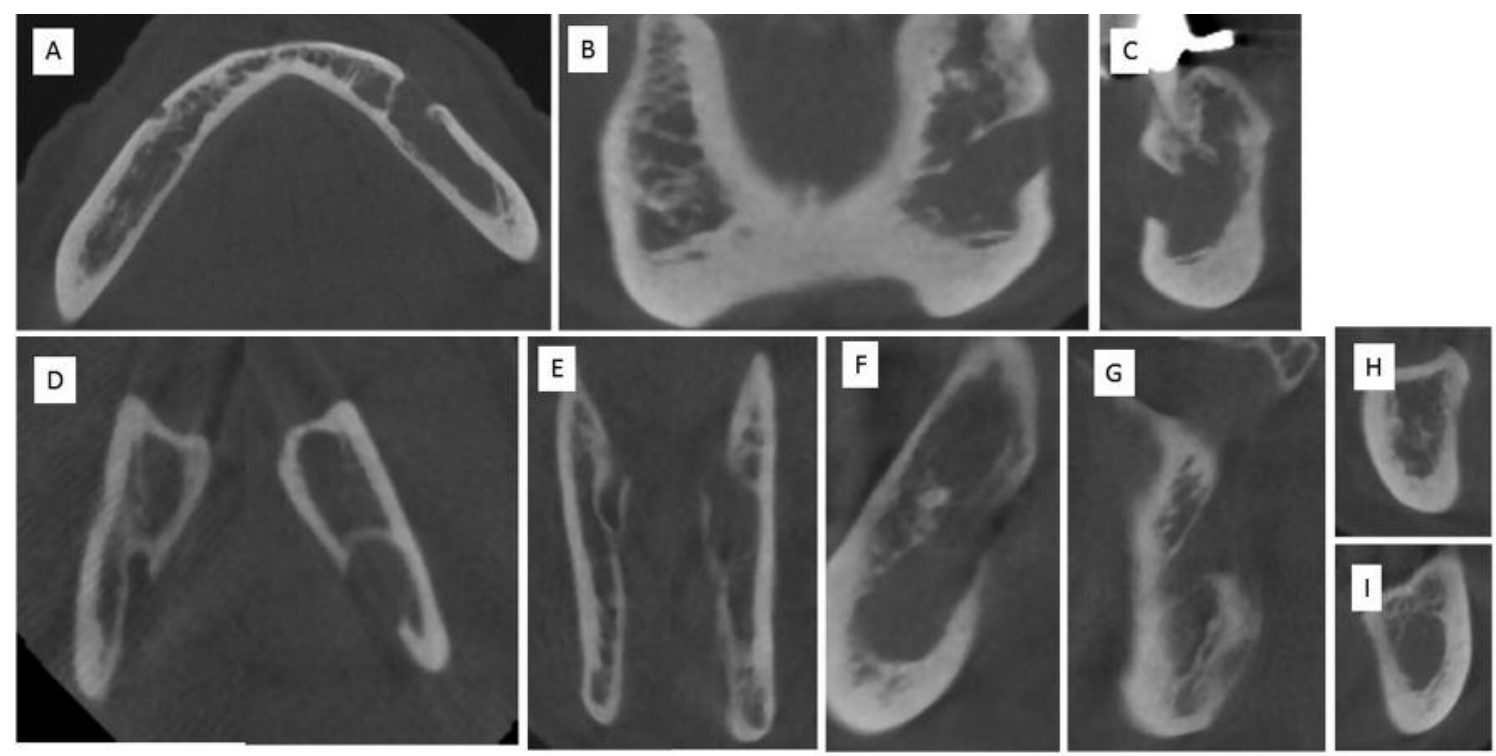

Figure 2. Cone beam computed tomography showing the enlarged foramina and canal of left mandibular side. In order to clarify the comparison of the findings, the regions of interest are presented as cropped images and assembled as one. The images show the considerable enlargement of the mental foramen (A: axial plane, B: coronal plane, $C$ : sagittal plane) and of the mandibular foramen [D: axial plane, E: coronal plane, F: sagittal plane (right side of mandible), G: sagittal plane: (left side of mandible)], right mandibular canal of normal size (H: coronal plane) and ill-defined, enlarged left mandibular canal (I: coronal plane). Side by side comparison shows extensive radiotranslucent region, indicating the widespread displacement of spongy bone in the left mandibular corpus and ramus. The spatial pattern of displacement of the bone acts as if the bone had been forced back in a centrifugal direction around the course of the inferior alveolar nerve. In contrast to panoramic tomography, the occupied space of the lesion is sharply demarcated in sectional images. However, neither imaging technique shows a marginal sclerotic zone surrounding the left canal.

Histology. The nerve tissue sample showed an intact nerve with adjacent lymphatic tissue (Figure 6).

The bone sample from the edge of the foramen showed regular, trabecular bone, with no signs of infiltration or destruction.

The hematoxylin and eosin-stained sections showed organoid lymphatic tissue, reminiscent of a lymph node, with prominent secondary follicles and typically structured germinal centers, suggesting the diagnosis of lymphatic hyperplasia. However, due to the fact that the findings were quite unusual for this particular anatomical location and due to some tissue crush artifacts, further immunohistochemical and clonality studies to corroborate the diagnosis were undertaken. These showed the typical composition of the Bcell-dependent follicular and T-cell-dependent inter-follicular zone, as revealed by antibodies against CD20 and CD3. The germinal centers were, as expected, positive for CD10 and BCL6 transcription repressor, and negative for BCL2 apoptosis regulator, with high proliferative index (Ki67). CD5 labeling corresponded to the CD3 positivity of the T-lymphocytes. Cyclin D1 staining was unremarkable. CD21 and CD23 highlighted networks of follicular dendritic cells. The tissue sample contained numerous IgG-positive plasma cells, with low $\operatorname{IgG} 4 / \mathrm{IgG}$ ratio (at most 6/high-power field), altogether without findings suspicious of IgG4-related sclerosing disease. The ratio of kappa- and lambda-positive plasma cells was balanced and there was no evidence of clonal immunoglobulin heavy chain $(I G H)$ and immunoglobulin light chain kappa (IGK) gene rearrangement in the polymerase chain reaction analysis (61).

In summary, the diagnosis of lymphatic hyperplasia was made (Figure 7).

\section{Discussion}

This case report shows that, by means of a detailed morphological examination, the diagnosis of an intraosseous lymphatic hyperplasia was made, for which a neoplasm of nerve sheath origin had been expected at this location. The development of lymphatic hyperplasia in the mental foramen has only been reported once, to our knowledge (60). However, this earlier case report differs in the phenotype from that presented here.

Oral lymphatics. The oropharyngeal region is densely supplied with lymphatic tissues. Discrete lymphatic aggregates are found in certain regions of the oral cavity, especially in the dorsolateral aspect of the tongue (lingual tonsil), ventral 

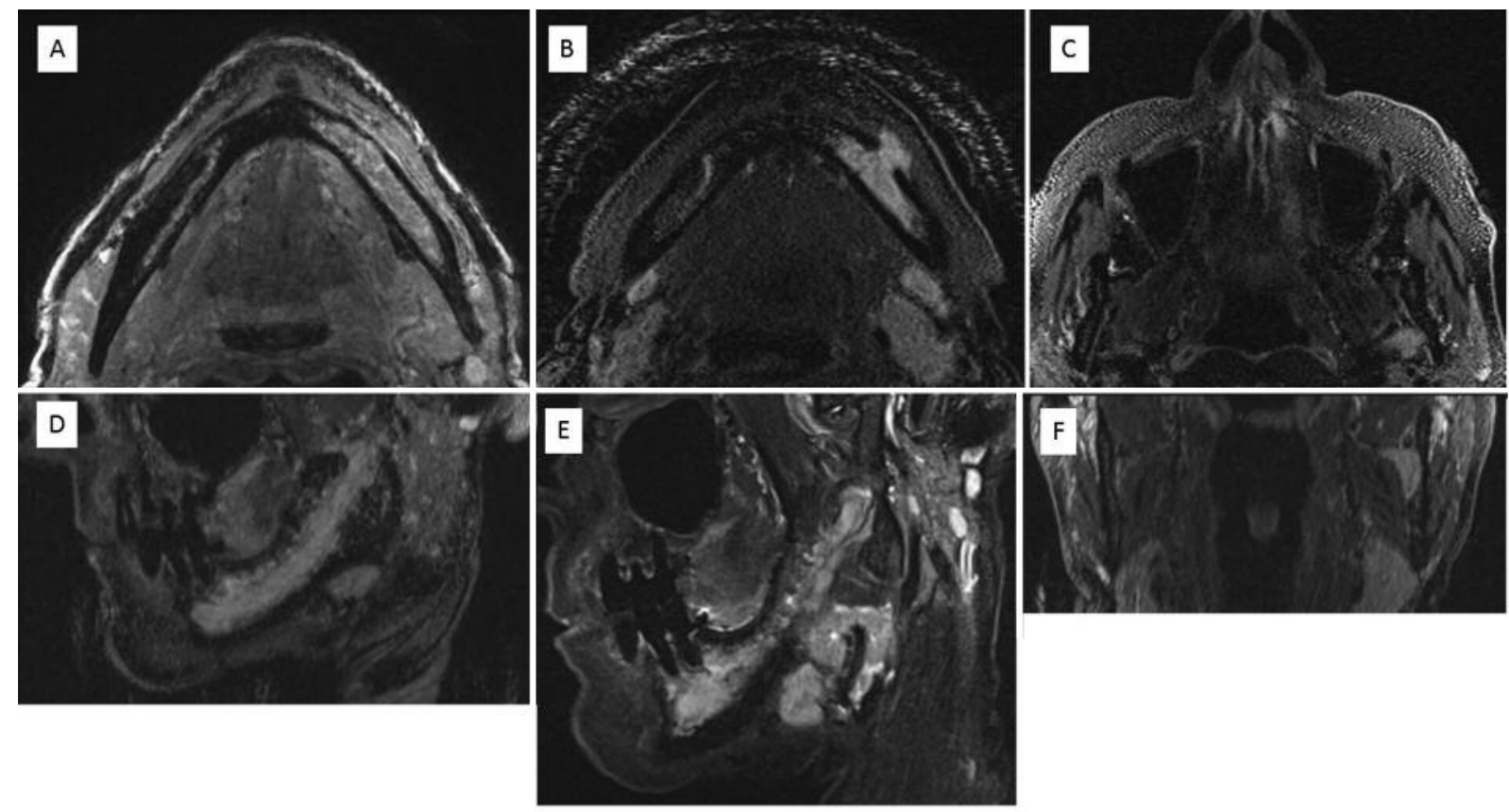

Figure 3. 7-Tesla magnetic resonance imaging of lymphatic hyperplasia affecting the mandibular nerve. A: Axial section of mandible shows alveolar inferior nerve of both sides (volume-interpolated breathhold examination). On the left side, the canal is densely filled with the hyperintense lesion. The intraluminal lesion is seen to be widely expanding at the expense of spongy bone. Inside the lesion appears less hyperintense than at the margins. Note image of normally sized right inferior alveolar nerve. B: Axial section of mandible: The intraosseous lesion expands in continuity to the soft tissues surrounding the foramen. Lesion is hyperintense in this mode and sharply demarcated from the soft tissues. C: Mandibular foramen depicted in same imaging mode. Lesion extends at this site in a similar way as to the mental foramen into soft tissues of the skull base (arrow). D: Parasagittal view of left mandible discloses the multiple, bulb-like extensions of the lesion to alveolar bone. E: This turbo spin-echo short-tau inversion recovery image shows periradicular extension of lesion. However, the marginal limbus of bone surrounding the dental roots is visible in continuity and differentiated from the lesion's hyperintensity by a small hypointense rim. F: Coronal view of mandibular foramen depicts the extraosseous part of the lesion closely adhering to the lingual aspect of mandibular ramus.

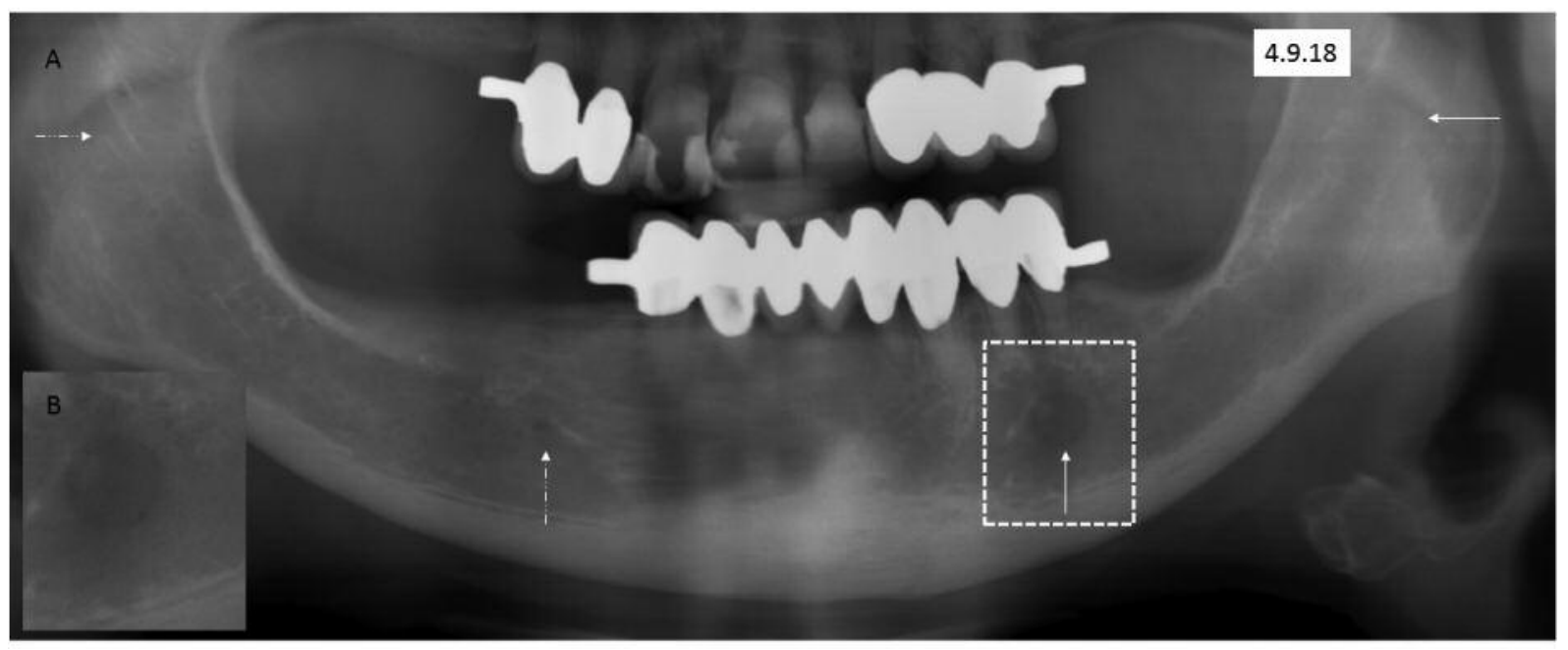

Figure 4. A: Panoramic view taken at the time of surgical intervention (age: 60 years). Horizontal broken arrow shows right mandibular foramen of normal size and position. Vertical broken arrow shows right mental foramen of normal size and position. Horizontal arrow shows enlarged mandibular foramen with more caudally located inferior border. Vertical arrow shows large roundish mental foramen. B: Enlarged view of inset region (dashed rectangle) in A. The mental foramen appeared to have enlarged compared to previous imaging 11 months before. 


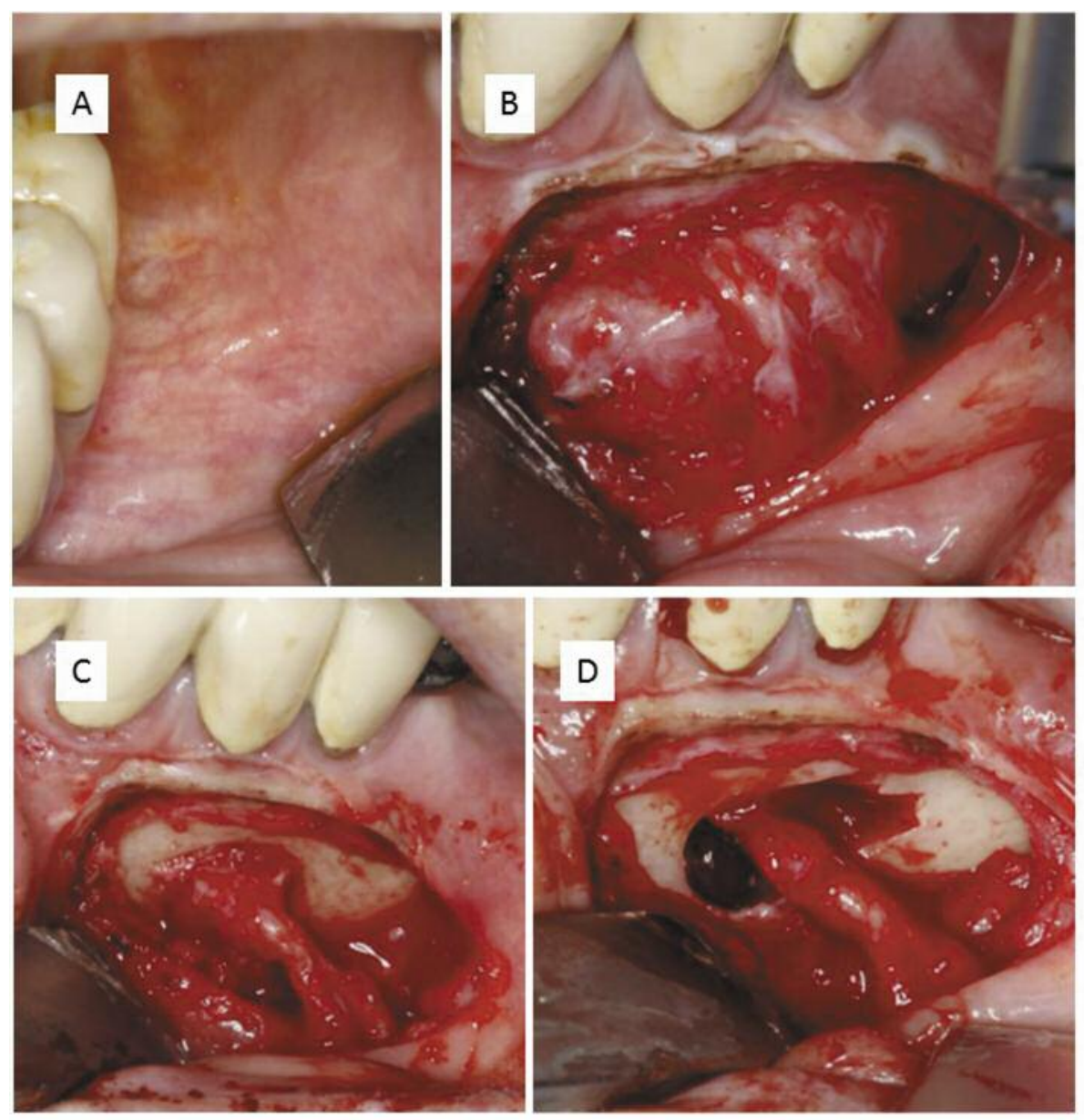

Figure 5. Surgical aspect. A: Healthy oral mucosa of left mandibular vestibule. B: After mucosal incision, the branches of the mental nerve appear, which are pushed out of the foramen by an obscure mass. C: Further preparation reveals the mental nerve and a homogeneous tumor mass, both of which fill in the enlarged foramen. D: Aspect of the foramen after removal of the tumor, taking a bone sample and a sample of the nerve.

portion of the tongue, buccal mucosa, floor of the mouth and soft palate (62). These aggregates may respond to appropriate stimuli with an excessive increase in size, which is interpreted as an expression of enhanced immune response. The normally flat and inconspicuous lymphatic aggregates can reach, as socalled reactive lymphatic hyperplasia, a tumor-like volume (62). In principle, lymphatic tissues outside of these anatomically preformed aggregates of the oral cavity are also capable of coordinated localized growth. Apparently, in our case, reactive lymphatic hyperplasia had developed inside the mandibular canal and emerged via the mental foramen to adjacent soft tissues. An odontogenic cause of the hyperplasia is unlikely, as the teeth were prosthetically restored, reacted adequately to cold stimuli and the nerve channels extending to the apices of the adjacent premolars were unaffected by the neoplasm. Lymphatic vessels of the cranial nerves and, in the periosteum or perichondrium, the mandible arise early in the embryonic phase (63). Lymphatic vessels are recognized in close contact with the alveolar nerve (64). Functions of these intraosseous lymphatic vessels are unknown. The granulomalike aspect of the tissue sample obtained during exploration is typical of lymphatic tissue (65).

Clinical findings and diagnosis. The clinical findings in this case are compatible with those for a benign lesion because the known tumor apparently had not shown an increase in volume over a long period of time, and because the nerve function had hardly been affected by the lesion. However, the unrestricted sensitivity of the skin of the chin is not a sure sign for excluding malignant lymphoma of the mandibular nerve branches. Indeed, sensory disturbances are a leading finding in the cutaneous field of the mental nerve in a lymphoma arising in the alveolar nerve or further proximally in the mandibular nerve $(15,20)$. This finding necessitates extended diagnosis of numb chin syndrome (47, 53). Nevertheless, a malignant tumor in this location does 

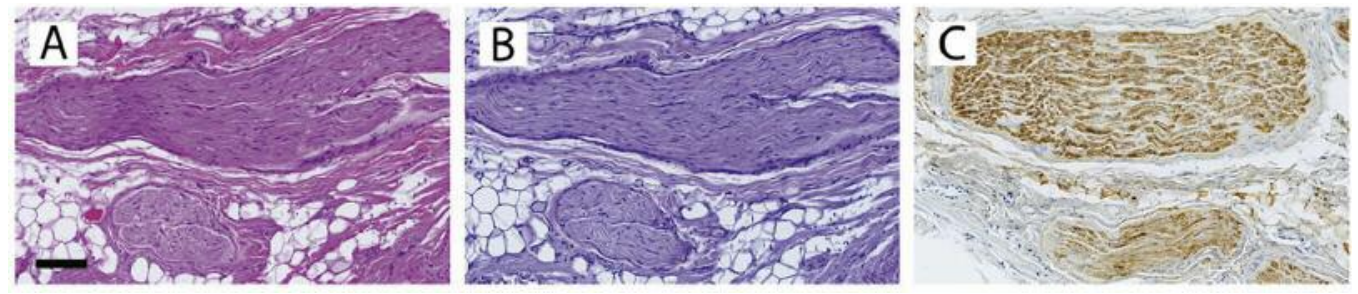

Figure 6. Histopathology of the nerve tissue sample shows single fascicles of a peripheral nerve without any pathological findings. A: Hematoxylin and eosin staining. B: Periodic acid-Schiff reaction. C: Immunohistochemistry for S100 protein. Scale bar: $100 \mu \mathrm{m}$.
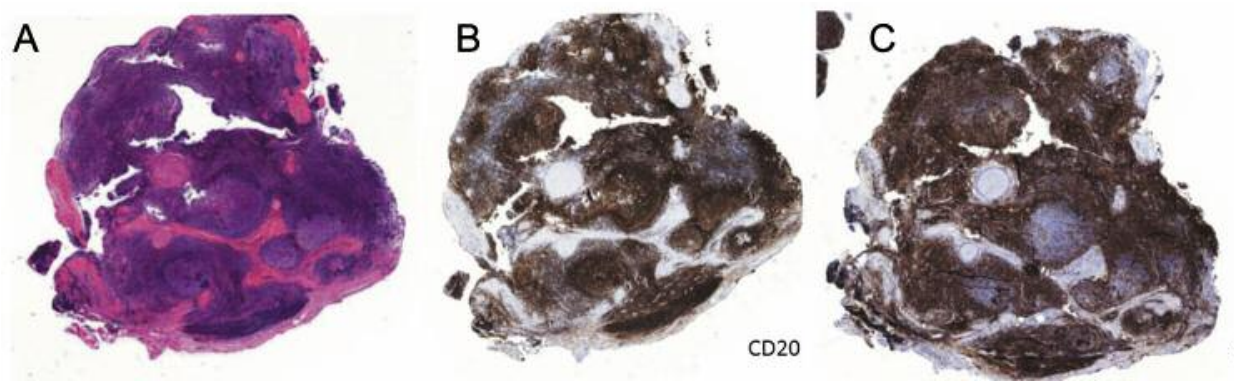

$\mathrm{CD} 3$

Figure 7. Lymphatic tissue of mandibular canal. A: The benign lymphatic tissue is reminiscent of a lymph node (hematoxylin-eosin staining). Immunohistochemical differentiation of lymphatic cells disclosed B-cells (B) and T-cells $(C)$.

not necessarily cause a numb chin (16). On the other hand, the intra-canalicular growth of a malignant tumor does not necessarily lead to an enlarged mental foramen $(15,46)$. Therefore, both imaging and physical findings are inappropriate for definitively assessing the biological quality of the lesion and histological investigation of a representative specimen is needed.

Taking into account the frequency of neoplasms of this region, the enlarged foramen in conjunction with the palpable nodular tumor had initially been assessed to be sporadic neurofibroma or schwannoma. Indeed, the (unilateral) enlargement of the mental foramen is considered a radiological finding of NF1 (27). Neurofibromas of the peripheral nerves as well as abnormal radiographic findings of the jaws were detected in NF1 $(27,33)$. However, our patient had no signs of NF1, so the suspected diagnosis was for sporadic tumor development. However, even with a very large sporadic neurofibroma of the mental nerve, the skeletal integrity of the foramen and canals can be preserved (28) so that radiological change does not give a reliable indication of the suspected cause. In fact, statements about tumor entity in cases of enlarged foramen and nerve without histological examination of the findings are dubious $(66,67)$.

Symmetry of nerves and asymmetry of bone. The mandibular foramina and the nerve channels show considerable inter- individual variations in size and topographical relationship to the teeth (4). However, these structures are very symmetrical within the individual. In panoramic radiography, the mandible is mapped as a symmetrical object of characteristic outline and differentiated internal structure, if the correct setting of the skull in the radiological device is maintained $(68,69)$. However, the lower jaw adapts to the disturbances of its main function under very variable conditions by changing its shape. That is, local morphological changes of the mandible are relatively common, which are interpreted as adapting to the main task of this bone, namely secure the tooth occlusion for shredding food, which is necessary in preparation for the swallowing act. Remarkably, the neural elements in this skeletal adaptation remain symmetrical in their macroscopic structure (8). Therefore, skeletal asymmetries of canal and foramina on radiographs can indicate the very rare case of asymmetric growth of nerves. This is a finding that should be further investigated. However, the quality of radiographic examination of the jaws with the panoramic view is very sensitive to positioning errors. Asymmetries of the nerve canal can be the result of positioning errors (67). In addition to erroneous assumption of skeletal asymmetry of the bone, local changes in shape and internal structure also can be simulated by positioning errors (70-72). For this reason, supplementary examinations, in particular imaging techniques, are recommended in cases of suspected asymmetry of the jaw 
(73). In the present case, the ramifications of the mental nerve were of normal size, so that the intraoperative findings supported the presumption that the tumor was adjacent to the nerve and had spread along the bone tube. Although the local findings derived from biopsy cannot be generalized for the entire nerve, everything indicated that the distension of the nerve canal was the result of lymphatic hyperplasia.

Quality of imaging. Panoramic view: The mental foramen can be displayed significantly enlarged on panoramic views, by up to $23 \%$ (2). Forni et al. identified an increase of the examined objects by as much as $36.6 \%$ on panoramic views compared to computed tomography (74). This influence apparently depends on the direction of displacement of the object in relation to the radiological measuring device (70). From these and other studies it was concluded that panoramic imaging is applicable to the qualitative assessment of structural strains, e.g. symmetry comparison, if correct alignment of the object to be examined in the beam path is respected, but caution is required for absolute measurement or relative comparison (59).

$C B C T$ : The quality of the presentation of skeletal structures of the facial skull has improved significantly with the introduction of CBCT. In panoramic radiography, the representation of the mandibular canal depends on where this anatomical entity is located relative to the radiological focal plane $(71,72)$. In contrast to panoramic radiography, CBCT can show the examined skeletal object as a cross-sectional image in various dimensions. However, CBCT also has limitations in imaging accuracy. For example, the diameter of the mandibular canal has been shown to be up to $22.8 \%$ smaller in the CBCT image than the true dimension of the organ (73).

MRI: MRI is capable of displaying lesions and tumors of the nerve canal and allows volume calculations $(75,76)$. Recent developments of MRI use 7-T and higher (77-79). Almost anatomical images can be achieved with these devices (77). However, 7-T MRI is sensitive to disturbance (79). Fundamental superiority of the imaging quality of MRI at 7-T versus 3-T is not yet assured for the presentation of tumors and lesions of the cranial nerves. In the present case, a tumor of the nerve sheath was considered possible according to MRI criteria. A statement on the nature of the tumor was not possible with MRI. The imaging quality of the lesion was excellent, however, it did not allow any distinction between the lesion and the nerve, which was clearly apparent on surgical exploration.

Lymphatic hyperplasia. Lymphatic hyperplasia (synonym: lymphoid hyperplasia) is a benign, reactive proliferation of lymphatic cells. Lymphatic hyperplasia may exhibit similarities to lymphoma, but the entity is clearly different due to its benign course, both from a clinical and morphological point of view (80). The immunohistochemical characteristics allow morphological distinction of lymphatic hyperplasia from neoplastic disease. Reactive lymphatic hyperplasia can originate at any site where lymphatic tissue is present.

Lymphatic hyperplasia of oral and maxillofacial regions: Particular attention has been paid to the differentiation of reactive lymphatic hyperplasia of the oral cavity, in particular the palate, because primary malignant lymphomas in the oral cavity occur preferentially in this area $(81,82)$. Lymphatic hyperplasia also occurs in other areas of the face, e.g. the orbit. However, lymphatic hyperplasia of the terminal branches of the trigeminal nerve is rare (83) and also in other head and neck regions a rare finding (84-87).

Lymphatic hyperplasia of the alveolar nerve: Vartiainen et al. reported a case in which lymphatic hyperplasia of the alveolar nerve was diagnosed (60). The case differs from this report in the substantial finding that the indication for surgical exploration was due to increasing numbness of the chin and cheek on the affected side. In the case of Vartiainen et al. (60), a biopsy of the nerve was made on suspicion of malignant tumor. Here, lymphatic hyperplasia was diagnosed in the histological evaluation and immunohistochemical differentiation of the lymphatic cells. Since this was a case of increasing neurological deficit, in a second procedure, the bone was osteotomized and the nerve removed. The tissue samples showed lymphatic infiltration of the nerve with necrosis. In contrast to the findings of the earlier report (60), in the case presented here, there were no functional failures of the nerve due to the disease and the tissue sample of the nerve showed neither infiltration by lymphatic tissue nor necrosis. However, our patient refused further surgical reduction of the lesion so that it cannot be assumed with certainty that the lesion was of the same histological type throughout. For both cases, the patients required careful follow-up (60).

\section{Conclusion}

Unilaterally enlarged mental foramen should be clarified diagnostically to exclude early findings of neoplastic diseases. Although tumors of the foramen can originate from the nerve itself, a lymphatic neoplasm is to be considered in the initial diagnosis. As a very rare diagnosis, after careful examination of the tissues, lymphatic hyperplasia may be found to have developed in the foramen. Imaging does not provide a safe assessment of tumor biology. Surgical exploration with detailed tissue examination of the tumor provides the basis for appropriate therapy.

\section{Conflicts of Interest}

The Authors declare that there are no conflicts of interest regarding this publication. 


\section{Authors' Contributions}

REF: Treated the patient, researched the relevant literature, and wrote the article. JM: examined and evaluated the tissue. WW: examined and evaluated the tissue. All Authors reviewed the article and released it for publication.

\section{Acknowledgements}

The Authors appreciate the cooperation with Dr. A. Heil, Neurographie Nord, Hamburg, who provided MRI of the patient's mandible. The Authors thank Professor A. Feller, Hämatopathologie, Kiel, for his consultative histological assessment of the case.

\section{References}

1 Tebo HG and Telford IR: An analysis of the variations in position of the mental foramen. Anat Rec 107: 61-66, 1950. PMID: 15413805.

2 Phillips JL, Weller RN and Kulild JC: The mental foramen: 3. Size and position on panoramic radiographs. J Endod 18: 383386, 1992. PMID: 1431694.

3 Gupta T: Localization of important facial foramina encountered in maxillo-facial surgery. Clin Anat 21: 633-640, 2008. PMID: 18773483. DOI: $10.1002 / \mathrm{ca} .20688$

4 von Arx T, Friedli M, Sendi P, Lozanoff S and Bornstein MM: Location and dimensions of the mental foramen: A radiographic analysis by using cone-beam computed tomography. J Endod 39: 1522-1528, 2013. DOI: 10.1016/j.joen.2013.07.033

5 Juodzbalys G, Wang HL and Sabalys G: Anatomy of mandibular vital structures. Part I: Mandibular canal and inferior alveolar neurovascular bundle in relation with dental implantology. J Oral Maxillofac Res 1: e2, 2010. PMID: 24421958. DOI: 10.5037/ jomr.2010.1102

6 Juodzbalys G, Wang HL and Sabalys G: Anatomy of mandibular vital structures. Part II: Mandibular incisive canal, mental foramen and associated neurovascular bundles in relation with dental implantology. J Oral Maxillofac Res 1: e3, 2010. PMID: 24421959. DOI: $10.5037 /$ jomr.2010.1103

7 Ikeda K, Ho KC, Nowicki BH and Haughton VM: Multiplanar MR and anatomic study of the mandibular canal. Am J Neuroradiol 17: 579-584, 1996. PMID: 8881258.

8 Captier G, Lethuilier J, Oussaid M, Canovas F and Bonnel F: Neural symmetry and functional asymmetry of the mandible. Surg Radiol Anat 28: 379-386, 2006. PMID: 16568217. DOI: 10.1007/s00276-006-0104-1

9 Lang J: Neuroanatomy of the optic, trigeminal, facial, glossopharyngeal, vagus, accessory and hypoglossal nerves. Arch Otorhinolaryngol 231: 1-69, 1981. PMID: 7020666

10 Lang J and Oder M: Biomorphosis of the mandible. Gegenbaurs Morphol Jahrb 130: 185-234, 1984. PMID: 6724279.

11 Gusenbauer AW, Katsikeris NF and Brown A: Primary lymphoma of the mandible: Report of a case. J Oral Maxillofac Surg 48: 409-415, 1990. PMID: 2179495.

12 Barber HD, Stewart JC and Baxter WD: Non-Hodgkin's lymphoma involving the inferior alveolar canal and mental foramen: report of a case. J Oral Maxillofac Surg 50: 1334-1336, 1992. PMID: 1447619.

13 Bertolotto M, Cecchini G, Martinoli C, Perrone R and, Garlaschi G: Primary lymphoma of the mandible with diffuse widening of the mandibular canal: Report of a case. Eur Radiol 6: 637-639, 1996. PMID: 8934126.

14 Hiraki A, Nakamura S, Abe K, Takenoshita Y, Horinouchi Y, Shinohara $M$ and Shirasuna K: Numb chin syndrome as an initial symptom of acute lymphocytic leukemia: report of three cases. Oral Surg Oral Med Oral Pathol Oral Radiol Endod 83: 555-561, 1997. PMID: 9159815.

15 Fan Y, Lukas R and Noronha A: Non-Hodgkin lymphoma presenting with numb chin syndrome. BMJ Case Rep 2011: bcr0120113712, 2011. PMID: 22696665. DOI: 10.1136/bcr.01. 2011.3712

16 Yamada T, Kitagawa Y, Ogasawara T, Yamamoto S, Ishii Y and Urasaki: Enlargement of mandibular canal without hypesthesia caused by extranodal non-Hodgkin's lymphoma: A case report. Oral Surg Oral Med Oral Pathol Oral Radiol Endod 89: 388-392, 2000. PMID: 10710468.

17 Benson RE, Rodd HD, North S, Loescher AR, Farthing PM and Payne M: Leukaemic infiltration of the mandible in a young girl. Int J Paediatr Dent 17: 145-150, 2007. PMID: 17263867. DOI: 10.1111/j.1365-263X.2006.00794.x

18 Buric N, Jovanovic G, Radovanovic Z, Buric M and Tijanic M: Radiographic enlargement of mandibular canal as first feature of non-Hodgkin's lymphoma. Dentomaxillofac Radiol 39: 383-388, 2010. PMID: 20729189. DOI: $10.1259 / \mathrm{dmfr} / 16059055$

19 Triantafillidou K, Dimitrakopoulos J, Iordanidis F and Gkagkalis A: Extranodal non-hodgkin lymphomas of the oral cavity and maxillofacial region: A clinical study of 58 cases and review of the literature. J Oral Maxillofac Surg 70: 2776-2785, 2012. PMID: 22494508. DOI: 10.1016/j.joms.2012.01.018

20 Hakkou F, Chbicheb S and El Wady W: Enlargement of mandibular canal and lower lip hypoesthesia revealing nonHodgkin's lymphoma of the mandible. Odontostomatol Trop 39: 9-14, 2016. PMID: 30230804.

21 Munhoz L, Marsan FP and Arita ES: Radiographic enlargement of mandibular canal as an extranodal primary Non-Hodgkin's lymphoma early sign in an asymptomatic patient. Case Rep Dent 2017: 9193165, 2017. PMID: 28299210. DOI: 10.1155/2017/ 9193165

22 Mårtensson $\mathrm{G}$ and Yden S: Technique for visualisation of the mental foramen: A case of an expanding soft tissue tumor in the mental foramen. Acta Radiol 42: 266-268, 1954. PMID: 13206827.

23 Ellis GL, Abrams AM and Melrose RJ: Intraosseous benign neural sheath neoplasms of the jaws. Report of seven new cases and review of the literature. Oral Surg Oral Med Oral Pathol 44: 731-743, 1977. PMID: 270070.

24 Larsson A, Praetorius F and Hjörting-Hansen E: Intraosseous neurofibroma of the jaws. Int J Oral Surg 7: 494-499, 1978. PMID: 102607.

25 Chen SY and Miller AS: Neurofibroma and schwannoma of the oral cavity. A clinical and ultrastructural study. Oral Surg Oral Med Oral Pathol 47: 522-528, 1979. PMID: 286274.

26 Sciubba JJ and Sachs SA: Schwannoma of the inferior alveolar nerve in association with the organ of Chievitz. J Oral Pathol 9: 16-28, 1980. PMID: 6767819.

27 Shapiro SD, Abramovitch K, Van Dis ML, Skoczylas LJ, Langlais RP, Jorgenson RJ, Young RS and Riccardi VM: Neurofibromatosis: Oral and radiographic manifestations. Oral Surg Oral Med Oral Pathol 58: 493-498, 1984. PMID: 6436765 . 
28 da Rosa MR, Ribeiro AL, de Menezes SA, Pinheiro JJ and Alves-Junior SM: Solitary giant neurofibroma of the mental nerve: A trauma-related lesion? J Craniofac Surg 24: e247-e251, 2013. PMID: 23714979. DOI: 10.1097/SCS.0b013e3182869f03

29 Kowatsch E, Feichtinger M, Zemann W, Karpf E and Kärcher $\mathrm{H}$ : Extraosseous schwannoma of the mental nerve clinically simulating intraosseous. J Oral Pathol Med 35: 517-519, 2006. PMID: 16918605.

30 Minowa K, Sakakibara N, Yoshikawa K, Ohmori K, Kitagawa $\mathrm{Y}$, Inoue $\mathrm{N}$, Totsuka $\mathrm{Y}$ and Nakamura $\mathrm{M}$ : $\mathrm{CT}$ and MRI findings of intraosseous schwannoma of the mandible: A case report. Dentomaxillofac Radiol 36: 113-116, 2007. PMID: 17403891

31 Imaizumi A, Kodama S, Sakamoto J, Sasaki Y, OtonariYamamoto M, Kuribayashi A, Kurabayashi $\mathrm{T}$ and Sano T: Imaging findings of benign peripheral nerve sheath tumor in jaw. Oral Surg Oral Med Oral Pathol Oral Radiol 116: 369-376, 2013. PMID: 23953423. DOI: 10.1016/j.oooo.2013.06.010

32 Suga K, Ogane S, Muramatsu K, Ohata H, Uchiyama T, Takano N, Shibahara T, Eguchi J, Murakami S and Matsuzaka K: Intraosseous schwannoma originating in inferior alveolar nerve: a case report. Bull Tokyo Dent Coll 54: 19-25, 2013. PMID: 23614949. DOI: $10.2209 /$ tdcpublication.54.19

33 Visnapuu V, Peltonen S, Alivuotila L, Happonen RP and Peltonen J: Craniofacial and oral alterations in patients with neurofibromatosis 1. Orphanet J Rare Dis 13: 131, 2018. PMID: 30092804. DOI: 10.1186/s13023-018-0881-8

34 Probst M, Koerdt S, Ritschl LM, Bissinger O, Liesche F, Gempt J, Meyer B, Burian E, Lummel $\mathrm{N}$ and Kolk A: Malignant peripheral nerve sheath tumor in the course of the mandibular nerve. World Neurosurg 117: e130-e137, 2018. PMID: 29883816. DOI: 10.1016/j.wneu.2018.05.203

35 Yagan R, Radivoyevitch M and Bellon EM: Involvement of the mandibular canal: early sign of osteogenic sarcoma of the mandible. Oral Surg Oral Med Oral Pathol 60: 56-60, 1985. PMID: 3862014.

36 Petrikowski CG, Pharoah MJ, Lee L and Grace MG: Radiographic differentiation of osteogenic sarcoma, osteomyelitis, and fibrous dysplasia of the jaws. Oral Surg Oral Med Oral Pathol Oral Radiol Endod 80: 744-750, 1995. PMID: 8680984.

37 Liu H, Chen X, Wan T and Li R: Chondrosarcoma in the mental foramen region of the mandible: A case report. Oncol Lett 12: 2081-2083, 2016. PMID: 27602143. DOI: 10.3892/ol.2016.4863

$38 \mathrm{Yu} \mathrm{Y,} \mathrm{Xiao} \mathrm{J,} \mathrm{Wang} \mathrm{L} \mathrm{and} \mathrm{Yang} \mathrm{G:} \mathrm{Low-grade} \mathrm{myofibroblastic}$ sarcoma in the mandibular canal: A case report. J Oral Maxillofac Surg 74: 1505.e1-e5, 2016. PMID: 27020841. DOI: 10.1016/j.joms.2016.02.025

39 Whitehouse GH: Radiological bone changes produced by intraoral squamous carcinomata involving the lower alveolus. Clin Otolaryngol Allied Sci 1: 45-52, 1976. PMID: 1031341.

40 Schmidseder R and Dick H: Spread of epidermoid carcinoma of the lip along the inferior alveolar nerve. Oral Surg Oral Med Oral Pathol 43: 517-520, 1977. PMID: 265477.

41 Anderson C, Krutchkoff D and Ludwig M: Carcinoma of the lower lip with perineural extension to the middle cranial fossa. Oral Surg Oral Med Oral Pathol 69: 614-618, 1990. PMID: 2333214.

42 Hell B and Freitag V: Lower lip carcinoma. Infiltration of the mandible along the mental nerve. J Craniomaxillofac Surg 16: 76-79, 1988. PMID: 3162243.
43 Bagatin M, Orihovac Z and Mohammed AM: Perineural invasion by carcinoma of the lower lip. J Craniomaxillofac Surg 23: 155-159, 1995. PMID: 7673442. DOI: 10.1016/S1010-5182 (05) 80004-6

44 Zupi A, Mangone GM, Piombino P and Califano L: Perineural invasion of the lower alveolar nerve by oral cancer: A follow-up study of 12 cases. J Craniomaxillofac Surg 26: 318-321, 1998. PMID: 9819683.

45 Sundar GT, Sherigar V, Shetty SS, Satya S and Gohil SM: Mandibular canal widening and Bell's palsy: Sequelae of perineural invasion in oral cancer. Case Rep Dent 2016: 3010934, 2016. PMID: 28025626. DOI: 10.1155/2016/3010934

46 Friedrich RE: Mental neuropathy (numb chin syndrome) leading to diagnosis of metastatic mediastinal cancer. Anticancer Res 30: 1819-1821, 2010. PMID: 20592385.

47 Friedrich RE, Heiland M, Assaf AT and Riecke B: Cone beam computed tomography in the differential diagnosis of mental neuropathy (numb chin syndrome) in metastatic colon cancer. Anticancer Res 33: 1757-1760, 2013. PMID: 23564829.

48 Kadom N, Egloff A, Obeid G, Bandarkar A and Vezina G: Juvenile mandibular chronic osteomyelitis: multimodality imaging findings. Oral Surg Oral Med Oral Pathol Oral Radiol Endod 111: e38-e43, 2011. PMID: 21310348. DOI: 10.1016/ j.tripleo.2010.10.027

49 Pass B, Guttenberg S, Childers EL and Emery RW: Soft tissue lipoma with the radiographic appearance of a neoplasm within the mandibular canal. Dentomaxillofac Radiol 35: 299-302, 2006. PMID: 16798930.

50 Choi HJ and Byeon JY: Symptomatic intraoral submuscular lipoma located nearby mental foramen. J Craniofac Surg 27: e457-e459, 2016. PMID: 27315319. DOI: 10.1097/ SCS.0000000000002770

51 Vaezeafshar R, Liu SY and Sidell D: Inferior alveolar nerve hemangioma. Laryngoscope 126: 2168-2170, 2016. PMID: 26863892 DOI: 10.1002/lary.25869

52 Sisman Y, Etöz OA, Mavili E, Sahman H and Tarim Ertas E: Anterior Stafne bone defect mimicking a residual cyst: A case report. Dentomaxillofac Radiol 39: 124-126, 2010. PMID: 20100926. DOI: $10.1259 / \mathrm{dmfr} / 49320253$

53 Assaf AT, Jürgens TP, Benecke AW, Riecke B, Blessmann M, Zrnc TA, Much CC, Heiland M and Friedrich RE. Numb chin syndrome: A rare and often overlooked symptom. J Oral Facial Pain Headache 28: 80-90, 2014. PMID: 24482791. DOI: 10.11607/jop.994

54 Anneroth G and Heimdahl A: Syndrome of multiple mucosal neurofibromas, pheochromocytoma and medullary thyroid carcinoma. Report of a case. Int J Oral Surg 7: 126-131, 1978.

55 Becktor KB, Becktor JP, Karnes PS and Keller EE: Craniofacial and dental manifestations of Proteus syndrome: A case report. Cleft Palate Craniofac J 39: 233-245, 2002. PMID: 11879083. DOI: 10.1597/1545-1569_2002_039_0233_cadmop_2.0.co_2

56 Toureno L and Park JH: Atypical orofacial conditions in Noonan syndrome: A case report. J Clin Pediatr Dent 36: 197-202, 2011. PMID: 22524084.

57 Ahlawat S, Fayad LM, Khan MS, Bredella MA, Harris GJ, Evans DG, Farschtschi S, Jacobs MA, Chhabra A, Salamon JM, Wenzel R, Mautner VF, Dombi E, Cai W, Plotkin SR and Blakeley JO: Whole-Body MRI Committee for the REiNS International Collaboration; REiNS International Collaboration Members 2016. 
Current whole-body MRI applications in the neurofibromatoses: NF1, NF2, and schwannomatosis. Neurology 87(7 Suppl 1): S31S39, 2016. PMID: 27527647. DOI: 10.1212/WNL.0000000 000002929

58 Bathla $\mathrm{G}$ and Hegde AN: The trigeminal nerve: An illustrated review of its imaging anatomy and pathology. Clin Radiol 68: 203-213. PMID: 22889460. DOI: 10.1016/j.crad.2012.05.019

59 Laher AE, Wells M, Motara F, Kramer E, Moolla M and Mahomed Z: Finding the mental foramen. Surg Radiol Anat 38: 469-476. PMID: 26464304. DOI: 10.1007/s00276-015-1565-x

60 Vartiainen VM, Siponen M, Salo T, Rosberg J and ApajaSarkkinen M: Widening of the inferior alveolar canal: a case report with atypical lymphocytic infiltration of the nerve. Oral Surg Oral Med Oral Pathol Oral Radiol Endod 106: e35-e39, 2008. PMID: 18675564. DOI: 10.1016/j.tripleo.2008.05.063

61 Mannu C, Gazzola A, Bacci F, Sabattini E, Sagramoso C, Roncolato F, Rossi M, Laginestra MA, Sapienza MR, Agostinelli C, De Leo A, Piccioli M, Righi S, Artioli P, Chilli L, Da Pozzo G, De Biase G, Sandri F, Pileri SA and Piccaluga PP: Use of IGK gene rearrangement analysis for clonality assessment of lymphoid malignancies: A single-center experience. Am J Blood Res 1: 167-174, 2011. PMID: 22432078.

62 Shafer WG, Hine MK and Levy BM: A textbook of oral pathology, fourth edition. Saunders, Philadelphia, pp. 31-32, 1983.

63 Cho KH, Cheong JS, Ha YS, Cho BH, Murakami G and Katori Y: The anatomy of fetal peripheral lymphatic vessels in the head-and-neck region: An immunohistochemical study. J Anat 220: 102-111, 2012. PMID: 22034965. DOI: 10.1111/j.14697580.2011.01441.x

64 Yaghmaei M, Mashhadiabbas F, Shahabi S, Zafarbakhsh A, Yaghmaei S and Khojasteh A: Histologic evaluation of inferior alveolar lymphatics: An anatomic study. Oral Surg Oral Med Oral Pathol Oral Radiol Endod 112: 564-567, 2011. PMID: 21333563. DOI: $10.1016 /$ j.tripleo.2010.11.013

65 Zhao H, Tang DZ, Zhu J, Zhang X, Tang YD and Li ST: Diffuse large B-cell lymphoma presented as trigeminal neuralgia: 2 cases reported and literature review. World Neurosurg 123: 383-389, 2019. PMID: 30528527. DOI: 10.1016/j.wneu.2018.11.217

66 Raakesh N, Sasikumar P, Manojkumar V and Govind GK: Progressively enlarging inferior alveolar nerve canal radiolucency - schwannoma? A rare intraosseous lesion. IJSS Case Rep Rev 2: 10-12, 2015. DOI: 10.17354/cr/2015/106

67 Ai CJ, Jabar NA, Lan TH and Ramli R: Mandibular canal enlargement: Clinical and radiological characteristics. J Clin Imaging Sci 7: 28, 2017. PMID: 28781925. DOI: 10.4103/ jcis.JCIS_28_17

68 Nortjé CJ, Farman AG and Grotepass FW: Variations in the normal anatomy of the inferior dental (mandibular) canal: A retrospective study of panoramic radiographs from 3612 routine dental patients. Br J Oral Surg 15: 55-63, 1977. PMID: 268217.

69 Farman AG, Nortjé CJ and Grotepass FW: Pathological conditions of the mandible: their effect on the radiographic appearance of the inferior dental (mandibular) canal. Br J Oral Surg 15: 64-74, 1977. PMID: 268218.

70 Xie Q, Soikkonen K, Wolf J, Mattila K, Gong M and Ainamo A: Effect of head positioning in panoramic radiography on vertical measurements: An in vitro study. Dentomaxillofac Radiol 25: 61-66, 1996. PMID: 9446974.

71 Laster WS, Ludlow JB, Bailey LJ and Hershey HG: Accuracy of measurements of mandibular anatomy and prediction of asymmetry in panoramic radiographic images. Dentomaxillofac Radiol 34: 343-349, 2005. PMID: 16227476.

72 Riecke B, Friedrich RE, Schulze D, Loos C, Blessmann M, Heiland $\mathrm{M}$ and Wikner J: Impact of malpositioning on panoramic radiography in implant dentistry. Clin Oral Investig 19: 781-790, 2015. PMID: 25074723. DOI: 10.1007/s00784-014-1295-1

73 Gerlach NL, Ghaeminia H, Bronkhorst EM, Bergé SJ, Meijer GJ and Maal TJ: Accuracy of assessing the mandibular canal on cone-beam computed tomography: a validation study. J Oral Maxillofac Surg 72: 666-671, 2014. PMID: 24480773. DOI: 10.1016/j.joms.2013.09.030

74 Forni A, Sánchez-Garcés MA and Gay-Escoda C: Identification of the mental neurovascular bundle: a comparative study of panoramic radiography and computer tomography. Implant Dent 21: 516-521, 2012. PMID: 23147166. DOI: 10.1097/ ID.0b01 $3 \mathrm{e} 318272 \mathrm{ff} 1 \mathrm{a}$

75 Srinivasan K, Seith A, Gadodia A, Sharma R, Kumar A, Roychoudhury A and Bhutia O: Evaluation of the inferior alveolar canal for cysts and tumors of the mandible-comparison of multidetector computed tomography and 3-dimensional volume interpolated breath-hold examination magnetic resonance sequence with curved multiplanar reformatted reconstructions. J Oral Maxillofac Surg 70: 2327-2332, 2012. PMID: 22265163. DOI: 10.1016/j.joms.2011.10.026

76 Kakizawa Y, Seguchi T, Kodama K, Ogiwara T, Sasaki T, Goto $\mathrm{T}$ and Hongo K: Anatomical study of the trigeminal and facial cranial nerves with the aid of 3.0-tesla magnetic resonance imaging. J Neurosurg 108: 483-490, 2008. PMID: 18312095. DOI: $10.3171 / \mathrm{JNS} / 2008 / 108 / 3 / 0483$

77 van Egmond SL, Visser F, Pameijer FA and Grolman W: Ex vivo and in vivo imaging of the inner ear at 7-Tesla MRI. Otol Neurotol 35: 725-729. PMID: 24557032. DOI: 10.1097/ MAO.0000000000000276

78 Grams AE, Kraff O, Kalkmann J, Orzada S, Maderwald S, Ladd ME, Forsting $M$ and Gizewski ER: Magnetic resonance imaging of cranial nerves at 7-Tesla. Clin Neuroradiol 23: 17-23, 2013. PMID: 23015059. DOI: 10.1007/s00062-012-0144-3

79 Voormolen EH, Diederen SJH, Woerdeman P, van der Sprenkel JWB, Noordmans HJ, Visser F, Viergever MA, Luijten P, Hoogduin $\mathrm{H}$ and Robe PA: Implications of extracranial distortion in ultra-high-field magnetic resonance imaging for image-guided cranial neurosurgery. World Neurosurg 126: e250-e258, 2019. PMID: 30797931. DOI: 10.1016/j.wneu.2019.02.028

80 Socolovsky M, Spaho N, Cueto DG, Doglietto F and Fernandez E: Reactive lymphoid follicular hyperplasia mimicking a peripheral nerve tumor. Surg Neurol 70: 514-517, 2008. PMID: 18261777. DOI: $10.1016 /$ j.surneu.2007.05.009

81 Napier SS and Newlands C: Benign lymphoid hyperplasia of the palate: Report of two cases and immunohistochemical profile. J Oral Pathol Med 19: 221-225, 1990. PMID: 1694245.

82 Anjomshoaa I, Bulford LA, Dym $\mathrm{H}$ and Woo SB: Florid follicular lymphoid hyperplasia of the hard palatal mucosa managed with intralesional steroids: A case report and review of the literature. J Oral Maxillofac Surg 71: 1202-1208, 2013. PMID: 23522767. DOI: 10.1016/j.joms.2013.01.015.

83 Prabhakaran VC, Crompton J, Singhall N, Madge SN and Selva D: Perineural involvement of the frontal nerve by benign lymphoid hyperplasia. Clin Exp Ophthalmol 36: 481-483, 2008. PMID: 18925918. DOI: 10.1111/j.1442-9071.2008.01797.x 
84 Hanemann JAC, de Carli ML, Dendena ER, do Couto Filho CEG, de Sousa SCOM, Pereira AAC, Giudice FS and Sperandio FF: Rare case report of an aggressive follicular lymphoid hyperplasia in maxilla. Oral Maxillofac Surg 21: 475-481, 2017. PMID: 29067544. DOI: 10.1007/s10006-017-0661-y

85 Sands NB and Tewfik M: Benign lymphoid hyperplasia of the tongue base causing upper airway obstruction. Case Rep Otolaryngol 2011: 625185, 2011. PMID: 22937372. DOI: $10.1155 / 2011 / 625185$

86 Lanier BJ and Cummings CW: Giant lymphoid hyperplasia presenting as a highly vascularized parapharyngeal mass. Otolaryngol Head Neck Surg 90: 426-430, 1982. PMID: 6817271.
87 Crous H, Gillam A, Kalokerinos MA, Knezevic S, Hobson P, Papadimos DL and Shield PW: Investigation of lymphoid lesions of the head and neck using combined fine needle aspiration cytology and flow cytometry: Accuracy and pitfalls. Cytopathology 30: 370-377, 2019. PMID: 30985042. DOI: 10.1111/cyt.12706

Received May 16, 2019

Revised June 17, 2019

Accepted June 20, 2019 